\title{
CALCULATION OF STRESS INTENSITY FACTOR USING DISPLACE- MENT EXTRAPOLATION METHOD IN PERIDYNAMIC FRAMEWORK
}

\author{
N. Zhu* \\ Department of Naval Architecture, Ocean and Marine Engineering \\ University of Strathclyde \\ Glasgow, UK \\ E. Oterkus \\ Department of Naval Architecture, Ocean and Marine Engineering \\ University of Strathclyde \\ Glasgow, UK
}

\begin{abstract}
This paper introduces a new approach to calculate stress intensity factors based on a combination of Displacement Extrapolation Method and Peridynamic Theory. After obtaining the displacement field from Peridynamic Theory, by appropriately selecting nodes at the crack tip region and their displacements yield stress intensity factors at the crack tips. To demonstrate the capability of the proposed approach, three different benchmark problems are considered including plate with a central crack, plate with an edge crack and plate with a slanted crack. Results evaluated from the current approach are compared against analytical and finite element analysis results, and good agreement is obtained between three different approaches. This shows that coupled Displacement Extrapolation Method and Peridynamic Theory approach can be an alternative method to calculate stress intensity factors.
\end{abstract}

Keywords: Stress Intensity Factor, Peridynamics, Displacement Extrapolation Method.

\section{INTRODUCTION}

Stress intensity factor was first introduced by Irwin [1] to describe the stress distribution around the crack tip region, and widely used to predict fatigue crack growth [2]. With the development of the calculation of SIF in the following years, several theoretical formulations had been developed to help researchers to determine the stress field around crack tips including central crack in an infinite plate under uniform uniaxial stress [3], edge crack in a plate under uniaxial stress [4] and slanted crack in a biaxial stress field [5] etc.

The numerical methods, such as Finite Element Method (FEM) and Boundary Element Method (FEM), provided researchers more choice to calculate the SIF. Analytical solutions were used in some studies for validation of numerical results. For example, both [6] and [7] used FEM to simulate stress intensity factor and compare the results with simple analytical solutions. Moreover, BEM was used by [8] to compute two-dimensional SIF and compared with the results calculated from displacement correlation method given by [9], [10] and [11]. The analytical solutions of SIF can be calculated based on various of formulations, such as formulations based on stress applied on the crack surface which can be calculated from the force applied on the model [12], and crack opening displacements (COD) were computed by [13] using the expression given by [14]. Lim et al. [15] summarised and compared different displacement-based stress intensity factor formulations. However, many researchers usually use numerical methods to simulate either displacement field or stress field around the crack tip area, and then use corresponding displacement-based or stress-based formulation to compute the stress intensity factor. For instance, Lazzarin and Tovo [16] used FEM to solve the stress field and then applied it to the formulation given by [17]. FEM had also been used by [18] to calculated the displacement field in order to compute the SIF. Similarly, BEM was used by [19] and [20] to simulate the stress and displacement field respectively, and then apply the results to the corresponding formulation to compute SIF. Unlike the most widely used FEM and BEM, both boundary collocation method (BCM) [21], finite difference method (FDM) [22] and extend finite element method (X-FEM) [23] can also be used to calculate the SIF. Due to the relationship between the strain energy release rate and stress intensity factor, both [24] and [25] used J-integral to compute the strain energy release rate around crack tip and then converted it to SIF. As an alternative approach, a new continuum mechanics

* Corresponding author (n.zhu@strath.ac.uk) 
formulation, peridynamics, can be used to determine SIF. Imachi et al. [26] determined mixed-mode dynamic SIFs by using ordinary-state based peridynamics based on the J-Integral value of the crack tip. Hu et al. [27] and Panchadhara and Gordon [28] presented a procedure to calculate J-Integral in bond-based peridynamic framework. Stenstrom and Eriksson [29] proposed a new procedure on J-Integral calculation in peridynamic framework by writing J-Integral as a function of displacement derivatives.

In this paper, a new approach is presented to determine SIF by using displacement extrapolation method (DEM) in peridynamic framework. Peridynamic (PD) theory is first used to obtain the displacement field around the crack surface. Then, by using the evaluated displacement field, DEM is utilized to compute the SIF. DEM was introduced by [30] and also been used by [23] to calculate SIF. Details of PD theory can be found in various studies available in the literature [31-42]. A brief information about PD theory will be given in the next section. To demonstrate the capability of the coupled DEM and PD approach to calculate SIFs, three benchmark cases are considered and PD results are compared with analytical and FEM results.

\section{PERIDYNAMIC THEORY}

The equation of motion of a material point in classical continuum mechanics (CCM) can be expressed as follows:

$$
\rho(\mathbf{x}) \ddot{\mathbf{u}}(\mathbf{x}, t)=\nabla \cdot \sigma+\mathbf{b}(\mathbf{x}, t)
$$

where $\rho(\mathbf{x})$ denotes density of the material and $\ddot{\mathbf{u}}(\mathbf{x}, t)$ represents the acceleration of the material point $\mathbf{x}$ at time $t$. Moreover, $\sigma$ and $\mathbf{b}(\mathbf{x}, t)$ represent the stress tensor and body force, respectively. Although the CCM equation of motion has been widely and successfully applied to different engineering problems, since there is a divergence operator $\nabla$ in Equation (1), this divergence operator brings significant limitations to this equation when solving a material system with discontinuities, such as cracks. According to [43], this limitation can be resolved by replacing the divergence operator with an integral term

$$
\rho(\mathbf{x}) \ddot{\mathbf{u}}(\mathbf{x}, t)=\int_{H_{\mathbf{x}}} \mathbf{f}\left(\mathbf{u}\left(\mathbf{x}^{\prime}, t\right)-\mathbf{u}(\mathbf{x}, t), \mathbf{x}^{\prime}-\mathbf{x}\right) d V_{\mathbf{x}^{\prime}}+\mathbf{b}(\mathbf{x}, t)
$$

where $\mathbf{u}(\mathbf{x}, t)$ represents the displacement of the material point $\mathbf{x}$ at time $t, V_{\mathbf{x}^{\prime}}$ represents the volume of the material point, and $\mathbf{f}\left(\mathbf{u}\left(\mathbf{x}^{\prime}, t\right)-\mathbf{u}(\mathbf{x}, t), \mathbf{x}^{\prime}-\mathbf{x}\right)$ represents PD bond force between two material points, $\mathbf{x}$ and $\mathbf{x}^{\prime}$. As shown in Figure 1, the material point, $\mathbf{x}$ interacts not only with its neighbouring material points but also other points within a specific region $H_{\mathbf{x}}$, which is called horizon [44]. The choice of the radius of the horizon, $\delta$, depends on the physical mechanisms that the model can correctly represent [45].

Madenci and Oterkus [31] provided the expression of the PD bond force between material points $\mathbf{x}$ and $\mathbf{x}^{\prime}$ of elastic material shown below:

$$
\mathbf{f}\left(\mathbf{u}^{\prime}-\mathbf{u}, \mathbf{x}^{\prime}-\mathbf{x}\right)=\operatorname{cs}\left(\mathbf{u}^{\prime}-\mathbf{u}, \mathbf{x}^{\prime}-\mathbf{x}\right) \frac{\mathbf{y}^{\prime}-\mathbf{y}}{|\mathbf{y} \prime-\mathbf{y}|}
$$

where $\mathbf{y}$ denotes the position of the material point $\mathbf{x}$ after deformation, and $c$ denotes the bond constant which contains the material information and can be expressed in terms of material constants of CCM. $s\left(\mathbf{u}^{\prime}-\mathbf{u}, \mathbf{x}^{\prime}-\mathbf{x}\right)$ represents the stretch of a bond which can be expressed as:

$$
s\left(\mathbf{u}^{\prime}-\mathbf{u}, \mathbf{x}^{\prime}-\mathbf{x}\right)=\frac{\left|\mathbf{y}^{\prime}-\mathbf{y}\right|-\left|\mathbf{x}^{\prime}-\mathbf{x}\right|}{\left|\mathbf{x}^{\prime}-\mathbf{x}\right|}
$$




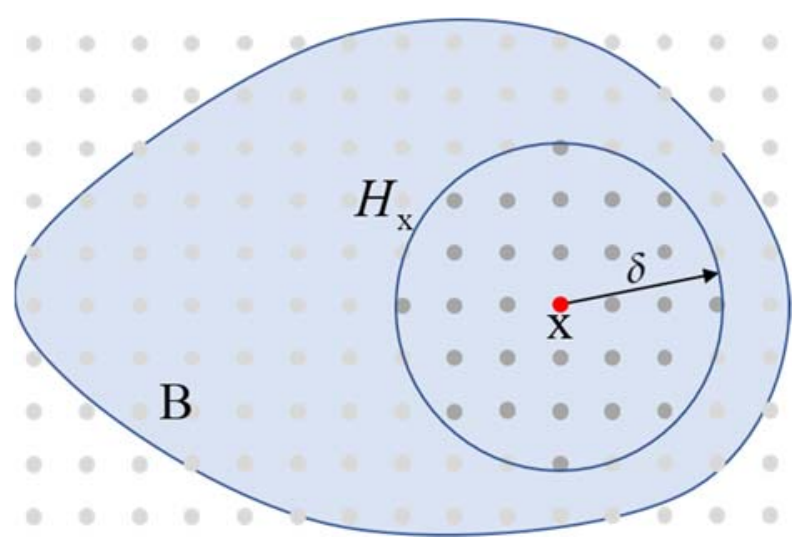

Fig. 1 Peridynamic Horizon.

For a linear elastic brittle material, the relationship between PD bond force and bond stretch are shown in Figure 2 .

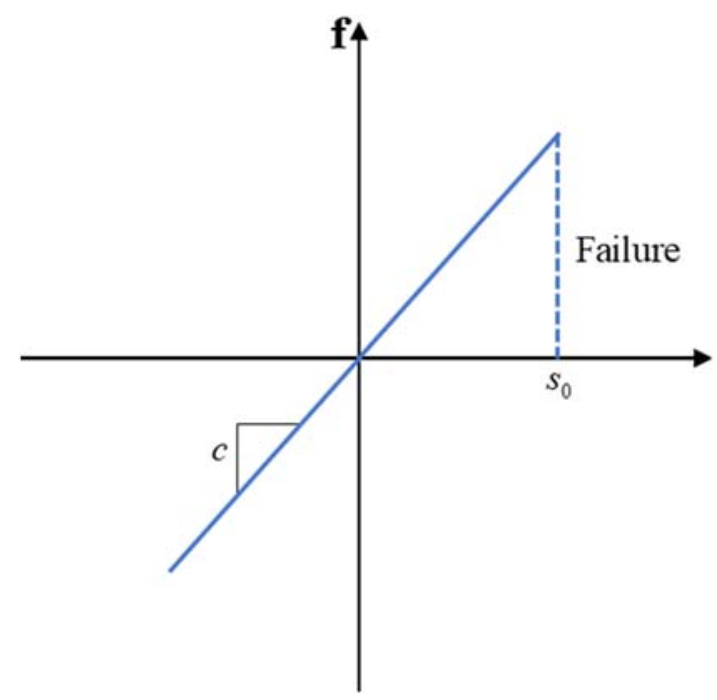

Fig. 2 Bond Constant and Critical Stretch for Linear Elastic Brittle Material.

In Figure 2, $s_{0}$ represents the critical stretch in PD theory, which means that if the stretch of a PD bond exceeds this critical value, the PD bond is broken, i.e. the bond force reduces to zero.

The surface effect (surface correction) was also considered in PD framework. Madenci and Oterkus [31] provided the procedure on how to take into account surface effects in PD framework.

\section{DISPLACEMENT EXTRAPOLATION METHOD}

The displacement field around crack tip under Mode I loading condition (Figure 4a) for linear elastic materials can be written as:

$$
\begin{aligned}
& u=\frac{K_{I}}{G} \sqrt{\frac{r}{2 \pi}} \cos \frac{\theta}{2}\left[\frac{\kappa-1}{2}+\sin ^{2} \frac{\theta}{2}\right] \\
& v=\frac{K_{I}}{G} \sqrt{\frac{r}{2 \pi}} \sin \frac{\theta}{2}\left[\frac{\kappa+1}{2}-\cos ^{2} \frac{\theta}{2}\right]
\end{aligned}
$$

where

$$
\kappa=\left\{\begin{array}{cc}
3-4 v & \text { plane strain } \\
\frac{3-v}{1+v} & \text { plane stress }
\end{array}\right.
$$




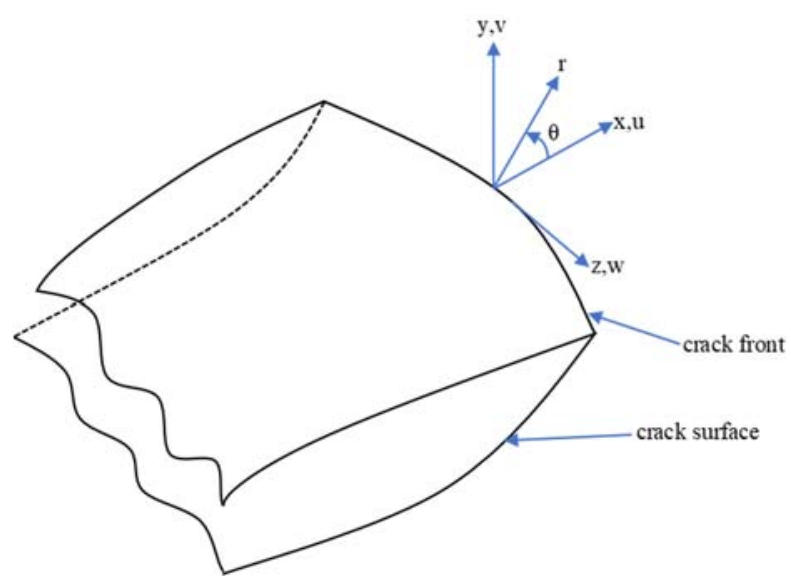

Fig. 3 Local Coordinate System around Crack Tip.

As shown in Figure 3, $u$ and $v$ are displacements in the local Cartesian coordinate system, $r$ and $\theta$ are the coordinates in the local cylindrical coordinate system at crack tip, $G$ and $v$ are shear modulus and Poisson's ratio of the material, and $K_{I}$ is the stress intensity factor under Mode I loading condition.

On the other hand, the displacement expressions for a crack tip under Mode II loading conditions (Figure 4b) can be expressed as:

$$
\begin{aligned}
& u=\frac{K_{I I}}{G} \sqrt{\frac{r}{2 \pi}} \sin \frac{\theta}{2}\left[\frac{\kappa+1}{2}+\cos ^{2} \frac{\theta}{2}\right] \\
& v=\frac{K_{I I}}{G} \sqrt{\frac{r}{2 \pi}} \cos \frac{\theta}{2}\left[\frac{\kappa-1}{2}+\sin ^{2} \frac{\theta}{2}\right]
\end{aligned}
$$

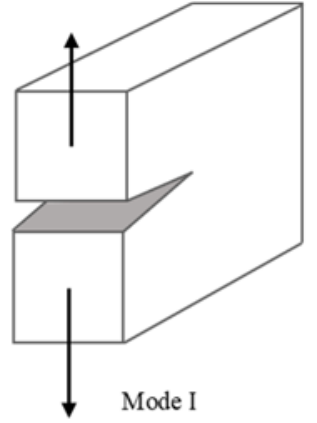

(a)

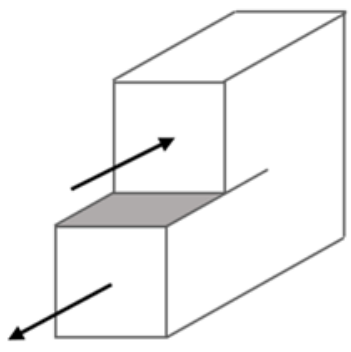

Mode II

(b)

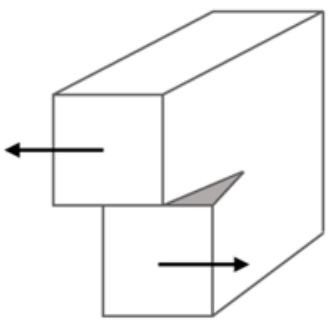

Mode III

(c)

Fig. 4 Fracture modes; (a) Mode I - crack opening, (b) Mode II - in-plane shear and (c) Mode III - out-of-plane shear.

where $K_{I I}$ is the Mode II stress intensity factor. Moreover, the displacement expression for a crack tip under Mode III loading (Figure 4c) can be expressed as:

$$
w=\frac{K_{I I I}}{G} \sqrt{\frac{2 r}{\pi}} \sin \frac{\theta}{2}
$$

where $K_{I I I}$ is the Mode III stress intensity factor. Hence, the actual displacements around the crack tip area for linear elastic materials under mixed-mode loading can be expressed as:

$$
u=\frac{1}{4 G} \sqrt{\frac{r}{2 \pi}}\left\{K_{I}\left[(2 \kappa-1) \cos \frac{\theta}{2}-\cos \frac{3 \theta}{2}\right]-K_{I I}\left[(2 \kappa+3) \sin \frac{\theta}{2}+\sin \frac{3 \theta}{2}\right]\right\}
$$




$$
\begin{gathered}
v=\frac{1}{4 G} \sqrt{\frac{r}{2 \pi}}\left\{K_{I}\left[(2 \kappa-1) \sin \frac{\theta}{2}-\sin \frac{3 \theta}{2}\right]-K_{I I}\left[(2 \kappa+3) \cos \frac{\theta}{2}+\cos \frac{3 \theta}{2}\right]\right\} \\
w=\frac{2 K_{I I I}}{G} \sqrt{\frac{r}{2 \pi}} \sin \frac{\theta}{2}
\end{gathered}
$$

where

$$
\kappa=\left\{\begin{array}{cc}
3-4 v & \text { plane strain } \\
\frac{3-v}{1+v} & \text { plane stress }
\end{array}\right.
$$

For material points located at crack surface $\left(\theta=180^{\circ}\right)$, equations (11), (12) and (13) can be rewritten as:

$$
\begin{gathered}
u=\frac{K_{I I}}{2 G} \sqrt{\frac{r}{2 \pi}}(1+\kappa) \\
v=\frac{K_{I}}{2 G} \sqrt{\frac{r}{2 \pi}}(1+\kappa) \\
w=\frac{2 K_{I I I}}{G} \sqrt{\frac{r}{2 \pi}}
\end{gathered}
$$

Therefore, the Mode I, Mode II and Mode III SIF for material points which are located at crack surface can be calculated through the displacements as

$$
\begin{aligned}
& K_{I}=\sqrt{2 \pi} \frac{G}{1+\kappa} \frac{|\Delta v|}{\sqrt{r}} \\
& K_{I I}=\sqrt{2 \pi} \frac{G}{1+\kappa} \frac{|\Delta u|}{\sqrt{r}} \\
& K_{I I I}=\sqrt{2 \pi} \frac{G}{1+\kappa} \frac{|\Delta w|}{\sqrt{r}}
\end{aligned}
$$

where $\Delta v, \Delta u$ and $\Delta w$ are the relative displacements of one crack face with respect to the other. For example, $|\Delta v|=\left|v_{K}-v_{M}\right|$ for points $\mathrm{K}$ and $\mathrm{M}$ shown in Figure 5(a).

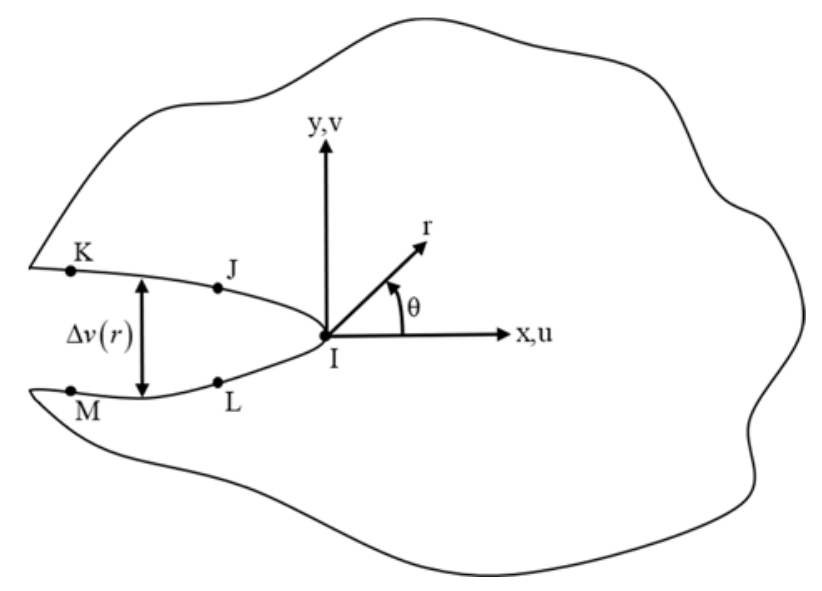

(a)

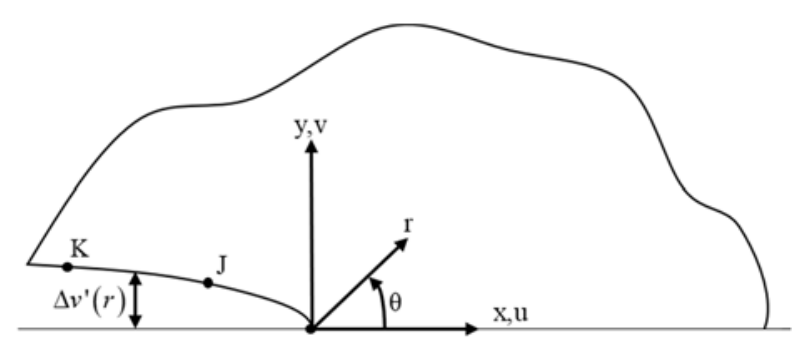

(b) 
As shown in Figure 5(a), in order to find the SIF at crack tip $(r=0)$, the only term needs to be considered is $\frac{|\Delta v|}{r}$ for the full crack model. Note that for symmetric problems with respect to the horizontal plane, it is sufficient to consider half of the model as shown in Figure 5(b) and the relative displacement can be calculated as $\Delta v=2 \cdot \Delta v^{\prime}$. It can be assumed that $\frac{|\Delta v|}{r}$ is a linear function for the material points at the crack surface

$$
\frac{|\Delta v|}{\sqrt{r}}=a+b \cdot r
$$

Unknown constants $a$ and $b$ can be determined with the displacements of the selected material points (point $\mathrm{K}$, $\mathrm{J}, \mathrm{M}$ and L in Figure 5). To calculate $K_{I}$ at the crack tip, $r \rightarrow 0$, Eq. (21) will yield as

$$
\lim _{r \rightarrow 0} \frac{|\Delta v|}{\sqrt{r}}=a
$$

Therefore, the stress intensity factor $K_{I}$ can be computed as

$$
K_{I}=\sqrt{2 \pi} \frac{G a}{1+\kappa}
$$

\section{IMPLEMENTATION OF DEM IN PD}

As described in previous section, it is essential to find the proper material points (including one for the crack tip location, and the other two for symmetric problems or four for other problems) to compute the stress intensity factor using DEM. The numerical implementation is done by implementing the peridynamic formulation in finite element framework as described in Macek and Silling [46]. The static solution is obtained by directly assigning zero to the inertia term and solving a matrix system. After the displacement field is obtained (as shown in Figure 6) and proper material points are selected (for example, point 41 and 42 in Figure 7), the Mode I stress intensity factor $K_{I}$ can be calculated using Equation (23) with the displacements $v$ of the selected material points. The flowchart of the process can be found in Figure 8.

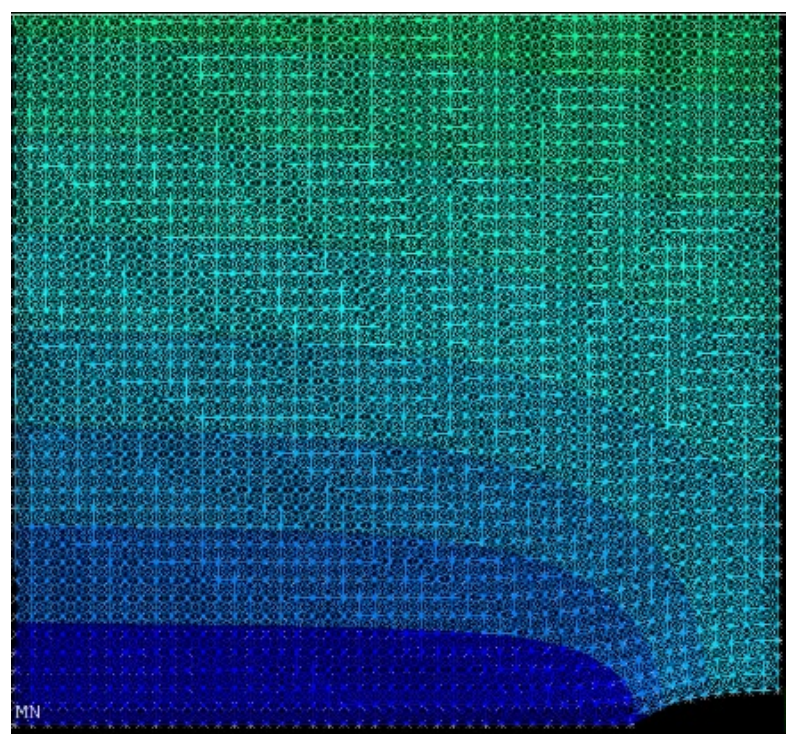

Fig. 6 Displacement Field around Crack Tip Area. 


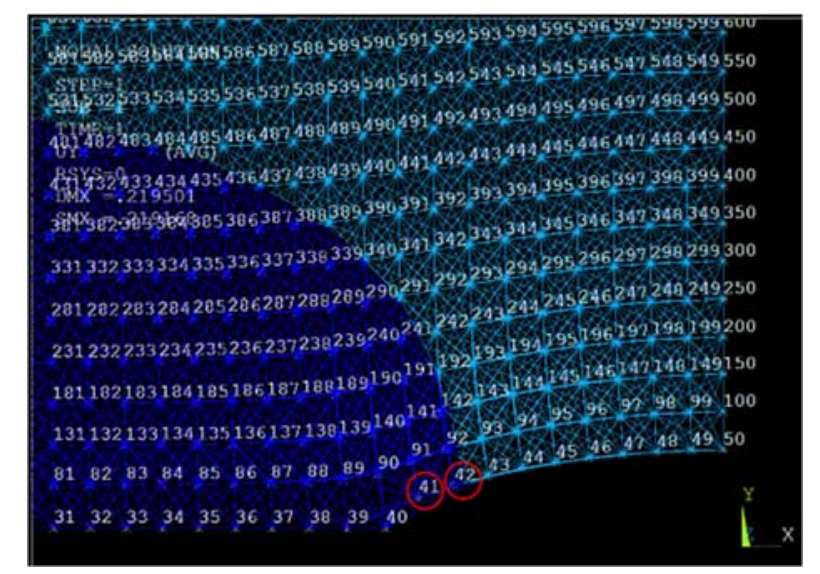

Fig. 7 Example of Points Selection to Calculate SIF

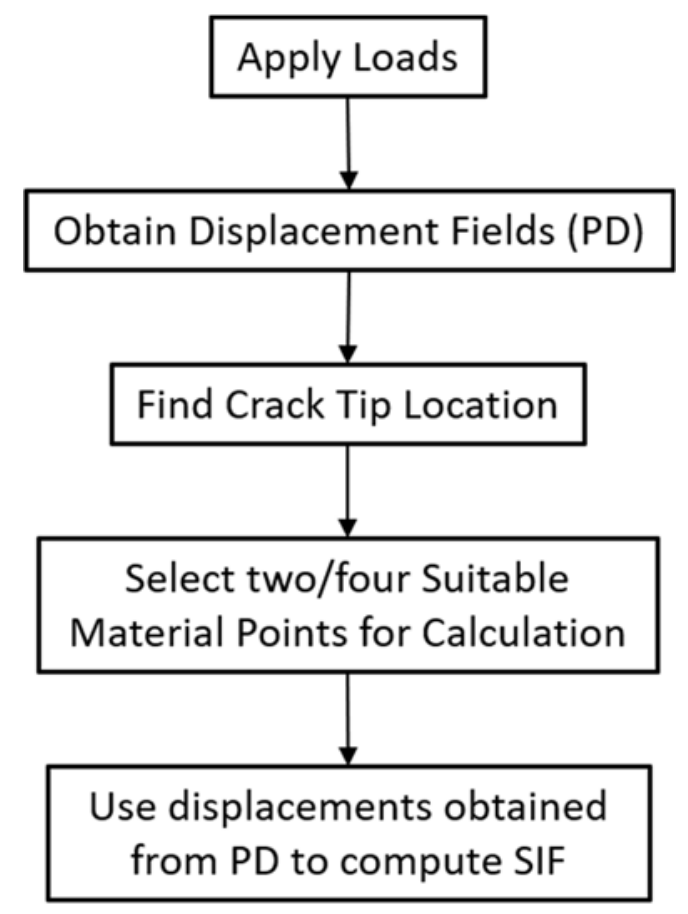

Fig. 8 Flowchart for Calculation of SIF.

\section{NUMERICAL RESULTS}

To verify the implementation of DEM in PD framework, several benchmark problems, starting from the simple central-cracked problem to the more complex slanted-cracked problem, were considered, and the results were compared with both analytical solutions and those computed by ANSYS. 


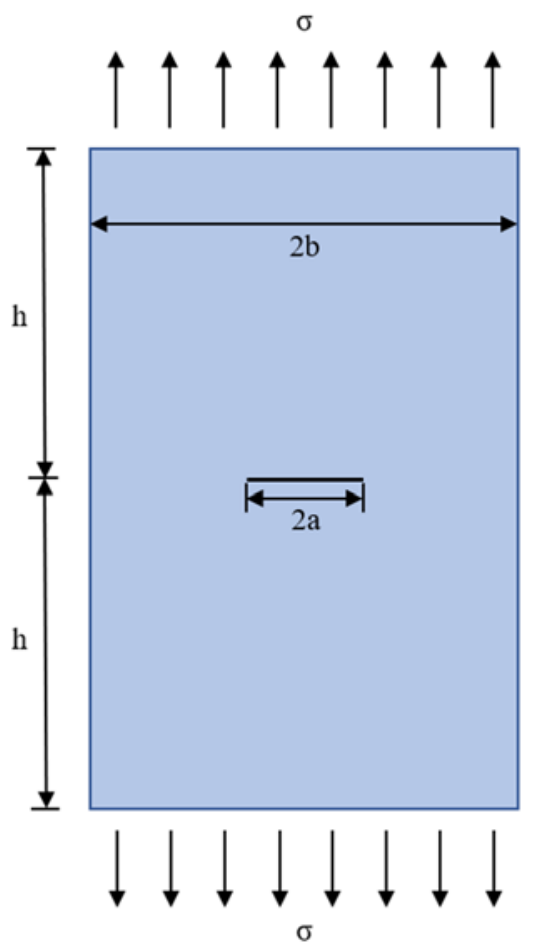

Fig. 9 Finite Plate with a Central Crack.

\subsection{Plate with a central crack}

The first problem that was considered was a finite width plate with a crack at the center. As shown in Figure 9, the width and height of the plate were $(2 b=) 2 \mathrm{~m}$ and $(2 h=) 4 \mathrm{~m}$, respectively, and a $(2 a=) 0.4 \mathrm{~m}$ long crack was located at the center of the plate. The elastic modulus was specified as $164.3 \mathrm{GPa}$, and the Poisson's ratio is 0.32 . A tension load of $183 \mathrm{MPa}$ was applied on both top and bottom edge of the plate.

For this particular configuration, Rooke and Cartwright [3] provided a theoretical equation on how to compute the Mode-I SIF for the plate with a central crack, which can be written as:

$$
K_{I}=\sigma \sqrt{\pi a}\left[\frac{1-\frac{a}{2 b}+0.326\left(\frac{a}{b}\right)^{2}}{\sqrt{1-\frac{a}{b}}}\right]
$$

For the PD simulation, the plate was discretised by $100 \times 200$ material points, and the thickness of the plate was specified as $0.02 \mathrm{~m}$. The normalised SIF calculated from PD was compared with the result computed from equation (24) and the result calculated from ANSYS, a commercial finite element software, by using the KCALC command. Table 1 shows results and the comparison between PD, analytical and ANSYS results. According to these results, SIF calculated from PD theory agree very well with the analytical and ANSYS results. The difference between PD and analytical results is less than 5\% whereas the difference between PD and ANSYS results is less than 3\%.

Table 1 Summary of SIF Results (Plate with a Central Crack).

\begin{tabular}{|l|l|l|}
\hline & Mode I normalised SIF $\left(K_{I} / \sigma \sqrt{\pi a}\right)$ & Difference \\
\hline PD & 1.0541 & \\
\hline Equation (24) & 1.0050 & $4.87 \%$ \\
\hline ANSYS & 1.0265 & $2.69 \%$ \\
\hline
\end{tabular}

\subsection{Plate with an edge crack}

The second problem which was considered was a plate with an edge crack, as shown in Figure 10. As shown in Figure 10 , the width and height of the plate were $(b=) 1 \mathrm{~m}$ and $(2 h=) 4 \mathrm{~m}$, respectively, and a $(a=) 0.2 \mathrm{~m}$ long crack 
was located at the left edge of the plate. The material properties and the tension load are the same as in the first problem.

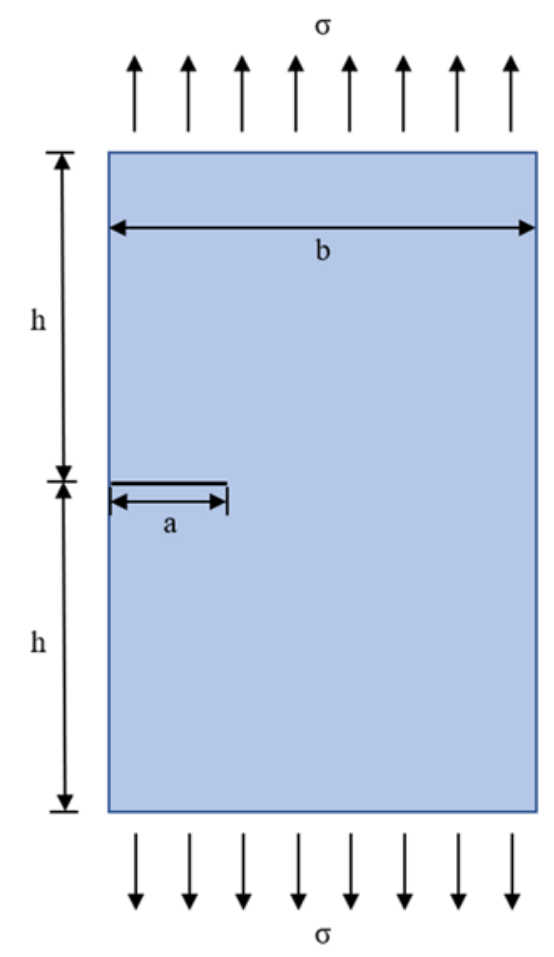

Fig. 10 Plate with an Edge Crack.

For this particular configuration, the SIF can be calculated as:

$$
K_{I}=1.12 \sigma \sqrt{\pi a}
$$

The plate was also discretized by $100 \times 200$ material points and the PD SIF result was compared with that computed by equation (25) given by [30] and ANSYS, which can be shown in Table 2. Again, a good agreement is obtained between PD, analytical and ANSYS results. The difference between PD and analytical results is less than $4 \%$ whereas the difference between PD and ANSYS results is less than 5\%.

Table 2 Summary of SIF Results (Plate with an Edge Crack).

\begin{tabular}{|l|l|l|}
\hline & Mode I normalized SIF $\left(K_{I} / \sigma \sqrt{\pi a}\right)$ & Difference \\
\hline PD & 1.1637 & \\
\hline Equation $(25)$ & 1.1200 & $3.88 \%$ \\
\hline ANSYS & 1.1133 & $4.52 \%$ \\
\hline
\end{tabular}

\subsection{Plate with a slanted crack}

The third problem which was considered was a plate with a slanted crack at the center. As shown in Fig. 11, $\beta$ is the orientation of the crack surface with respect of $\mathrm{x}$-axis. The width and height of the plate were $(b=) 1 \mathrm{~m}$ and $(h=)$ $2 \mathrm{~m}$, respectively, and the central crack has a length of $(a=) 0.2 \mathrm{~m}$. 


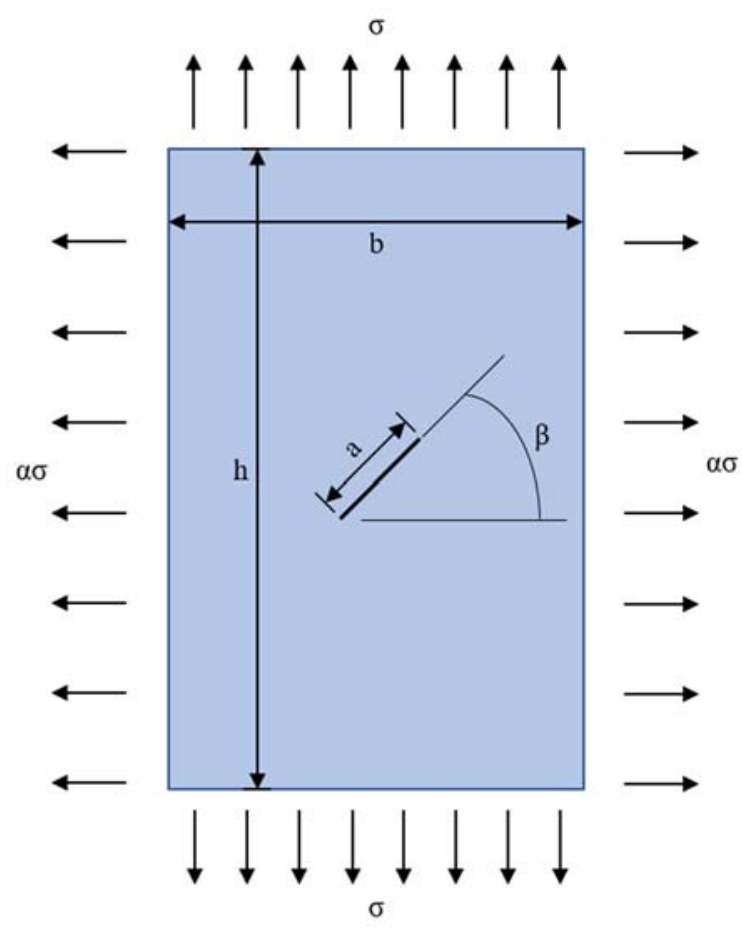

Fig. 11 Plate with a Slanted Crack.

The analytical form of SIF for slanted cracks can be expressed as [5]:

$$
K_{I}=\sigma \sqrt{\frac{\pi a}{2}}\left(\cos ^{2} \beta+\alpha \sin ^{2} \beta\right)
$$

and

$$
K_{I I}=\sigma \sqrt{\frac{\pi a}{2}}(1-\alpha) \sin \beta \cos \beta
$$

where $\alpha$ is the ratio between the tensile load applied horizontally and the load applied vertically. In this section, $\alpha$ was set to 0 , which means only tension loading is applied at the top and bottom edges of the plate, and $\beta$ was set to be 60 and 15 degree. The material properties and the tension load are the same as in the previous problem.

Unlike the PD simulation described in the previous two sections, the plate was discretized into $160 \times 320$ material points, and the results of both Mode I and Mode II SIFs were computed from PD and compared with SIFs calculated by using Equations (26) and (27). The results are given in Table 3:

Table 3 Summary of SIF Results (Plate with a $60^{\circ}$ Slanted Crack).

\begin{tabular}{|l|l|l|}
\hline$\beta=60^{\circ}$ & Mode I normalized SIF $\left(K_{I} / \sigma \sqrt{\pi a}\right)$ & Difference \\
\hline PD & 0.2702 & \\
\hline Equation (26) & 0.2506 & $7.82 \%$ \\
\hline & Mode II normalized SIF $\left(K_{I I} / \sigma \sqrt{\pi a}\right)$ & Difference \\
\hline PD & 0.4600 & \\
\hline Equation (27) & 0.4329 & $6.26 \%$ \\
\hline
\end{tabular}


Table 4 Summary of SIF Results (Plate with a $15^{\circ}$ Slanted Crack).

\begin{tabular}{|l|l|l|}
\hline$\beta=15^{\circ}$ & Mode I normalized SIF $\left(K_{I} / \sigma \sqrt{\pi a}\right)$ & Difference \\
\hline PD & 1.0022 & \\
\hline Equation (26) & 0.9332 & $7.40 \%$ \\
\hline & Mode II normalized SIF $\left(K_{I I} / \sigma \sqrt{\pi a}\right)$ & Difference \\
\hline PD & 0.2632 & \\
\hline Equation (27) & 0.2501 & $5.26 \%$ \\
\hline
\end{tabular}

As shown in the above tables, a very good agreement is obtained for both Mode I and Mode II SIFs between analytical and PD results. The difference between PD and analytical results is less than $8 \%$ for both Mode-I and Mode-II SIFs.

\section{DISCUSSION AND CONCLUSION}

In this study, a coupled Displacement Extrapolation Method and Peridynamic Theory approach is utilized to calculate stress intensity factors. To demonstrate the capability of the proposed approach, three different benchmark problems were considered including plate with a central crack, plate with an edge crack and plate with a slanted crack. Stress intensity factors obtained from Peridynamic Theory were compared against analytical and ANSYS results. For all three cases, it was observed that the results obtained with the current approach agree well with analytical and ANSYS results. The maximum difference between PD and analytical results is less than $8 \%$ for all cases including Mode-I and Mode-II SIFs. Finally, it can be concluded that the proposed approach can be used as an alternative approach to calculate stress intensity factors.

\section{REFERENCES}

1. Irwin, G. R., "Analysis of stresses and strains near the end of a crack traversing a plate, " Journal of Applied Mechanics, (1957).

2. Schijve, J., "Stress Intensity Factors of Cracks, " in Fatigue of Structures and Materials, Dordrecht: Springer Netherlands, (2009), pp. 105-140.

3. Rooke, D. P. and Cartwright, D. J., "Compendium of stress intensity factors, " Procurement Executive, Ministry of Defence. H. M. S. O., p. 330, (1976).

4. Liu, M., Gan, Y., Hanaor, D. A., Liu, B. and Chen, C., "An improved semi-analytical solution for stress at roundtip notches," Engineering Fracture Mechanics, 149, pp. 134-143, (2015).

5. Sih, G. C., Paris, P. C. and Erdogan, F., "Crack-tip, stress-intensity factors for plane extension and plate bending problems," Journal of Applied Mechanics, 29, no. 2, pp. 306-312, (1962).

6. Kishimoto, K., Aoki, S. and Sakata, M., "Simple formula for dynamic stress intensity factor of pre-cracked Charpy specimen," Engineering Fracture Mechanics, 13, no. 3, pp. 501-508, (1980).

7. Xiao, Z. M. and Chen, B. J., "Stress intensity factor for a Griffith crack interacting with a coated inclusion," International Journal of Fracture, 108, no. 3, pp. 193-205, (2001).

8. Blandford, G. E., Ingraffea, A. R. and Liggett, J. A., "Two-dimensional stress intensity factor computations using the boundary element method," International Journal for Numerical Methods in Engineering, 17, no. 3, pp. 387404, (1981).

9. Shih, C. F., de Lorenzi, H. G. and German, M. D., "Crack extension modeling with singular quadratic isoparametric elements," International Journal of Fracture, 12, no. 4, pp. 647-651, (1976).

10. Barsoum, R. S., "On the use of isoparametric finite elements in linear fracture mechanics," International Journal for Numerical Methods in Engineering, 10, no. 1, pp. 25-37, (1976).

11. Ingraffea, A. R., "On discrete fracture propagation in rock loaded in compression," in Proceedings, First International Conference on Numerical Methods in Fracture Mechanics, pp. 235-248, (1978),

12. Petroski, H. J. and Achenbach, J. D., "Computation of the weight function from a stress intensity factor," Engineering Fracture Mechanics, 10, no. 2, pp. 257-266, (1978).

13. Guinea, G. V., Pastor, J. Y., Planas, J. and Elices, M., "Stress intensity factor, compliance and CMOD for a general three-point-bend beam," International Journal of Fracture, 89, no. 2, pp. 103-116, (1998). 
14. Paris, P. C., "The Mechanics of Fracture Propagation and Solutions to Fracture Arrester Problem," in "Document D2-2195," The Boeing Company, (1957).

15. Lim, I. L., Johnston, I. W. and Choi, S. K., "Comparison between various displacement-based stress intensity factor computation techniques," International Journal of Fracture, 58, no. 3, pp. 193-210, (1992).

16. Lazzarin, P. and Tovo, R., "A notch intensity factor approach to the stress analysis of welds," Fatigue \& Fracture of Engineering Materials \& Structures, 21, no. 9, pp. 1089-1103, (1998).

17. Gross, B. and Mendelson, A., "Plane elastostatic analysis of V-notched plates," International Journal of Fracture Mechanics, 8, no. 3, pp. 267-276, (1972).

18. Rybicki, E. F. and Kanninen, M. F., "A finite element calculation of stress intensity factors by a modified crack closure integral," Engineering Fracture Mechanics, 9, no. 4, pp. 931-938, (1977).

19. Dominguez, J. and Gallego, R., "Time domain boundary element method for dynamic stress intensity factor computations," International Journal for Numerical Methods in Engineering, 33, no. 3, pp. 635-647, (1992).

20. Martínez, J. and Domínguez, J., "On the use of quarter-point boundary elements for stress intensity factor computations," International Journal for Numerical Methods in Engineering, 20, no. 10, pp. 1941-1950, (1984).

21. Zhu, Z., Wang, L., Mohanty, B. and Huang, C., "Stress intensity factor for a cracked specimen under compression," Engineering Fracture Mechanics, 73, no. 4, pp. 482-489, (2006).

22. Chen, Y. M., "Numerical computation of dynamic stress intensity factors by a Lagrangian finite-difference method (the HEMP code)," Engineering Fracture Mechanics, 7, no. 4, pp. 653-660, (1975).

23. Nagashima, T., Omoto, Y. and Tani, S., "Stress intensity factor analysis of interface cracks using X-FEM," International Journal for Numerical Methods in Engineering, 56, no. 8, pp. 1151-1173, (2003).

24. Parks, D. M., "A stiffness derivative finite element technique for determination of crack tip stress intensity factors," International Journal of fracture, 10, no. 4, pp. 487-502, (1974).

25. Miyazaki, N., Ikeda, T., Soda, T. and Munakata, T., "Stress intensity factor analysis of interface crack using boundary element method - application of contour-integral method," Engineering Fracture Mechanics, 45, no. 5, pp. 599-610, (1993).

26. Imachi, M., Tanaka, S. and Bui, T. Q., "Mixed-mode dynamic stress intensity factors evaluation using ordinary state-based peridynamics," Theoretical and Applied Fracture Mechanics, 93, pp. 97-104, (2018).

27. Hu, W., Ha, Y. D., Bobaru, F. and Silling, S. A., "The formulation and computation of the nonlocal J-integral in bond-based peridynamics," International Journal of Fracture, 176, no. 2, pp. 195-206, (2012).

28. Panchadhara, R. and Gordon, P. A., "Application of peridynamic stress intensity factors to dynamic fracture initiation and propagation," International Journal of Fracture, 201, no. 1, pp. 81-96, (2016).

29. Stenström, C. and Eriksson, K., “The J-contour integral in peridynamics via displacements," International Journal of Fracture, 216(2), pp.173-183, (2019).

30. Paris, P. C. and Sih, G. C., "Stress analysis of cracks," in Fracture toughness testing and its applications: ASTM International, pp. 30-81, (1965).

31. Madenci, E. and Oterkus E., Peridynamic Theory and Its Applications. New York: Springer, (2014).

32. Oterkus, S., Madenci, E. and Oterkus, E., "Fully coupled poroelastic peridynamic formulation for fluid-filled fractures," Engineering Geology, 225, pp. 19-28, (2017).

33. De Meo, D., Zhu, N. and Oterkus, E., "Peridynamic modelling of granular fracture in polycrystalline materials," Journal of Engineering Materials and Technology, 138, no. 4, 041008, (2016).

34. Oterkus, E., Guven, I. and Madenci, E., "Impact damage assessment by using peridynamic theory," Open Engineering, 2, no. 4, pp. 523-531, (2012).

35. Galadima, Y., Oterkus, E. and Oterkus, S., "Two-dimensional implementation of the coarsening method for linear peridynamics," AIMS Materials Science, 6, no. 2, pp. 252-275, (2019).

36. Basoglu, M. F., Zerin, Z., Kefal, A. and Oterkus, E., "A computational model of peridynamic theory for deflecting behavior of crack propagation with micro-cracks," Computational Materials Science, 162, pp. 33-46, (2019).

37. Javili, A., Morasata, R., Oterkus E. and Oterkus, S., "Peridynamics review," Mathematics and Mechanics of Solids, 1081286518803411, (2018).

38. Gao, Y. and Oterkus, S., "Ordinary state-based peridynamic modelling for fully coupled thermoelastic problems," Continuum Mechanics and Thermodynamics, pp. 1-31, (2018).

39. Madenci, E. and Oterkus, S., "Ordinary state-based peridynamics for thermoviscoelastic deformation," Engineering Fracture Mechanics, 175, pp. 31-45, (2017).

40. Gao, Y. and Oterkus, S., "Fully coupled thermomechanical analysis of laminated composites by using ordinary state based peridynamic theory," Composite Structures, 207, pp. 397-424, (2019). 
41. Oterkus, S. and Madenci, E., "Fully coupled thermomechanical analysis of fiber reinforced composites using peridynamics," 55th AIAA/ASME/ASCE/AHS/SC Structures, Structural Dynamics, and Materials ConferenceSciTech Forum and Exposition 2014, National Harbor, Maryland, USA (January 13-17, 2014).

42. Oterkus, E. and Madenci, E., "Peridynamics for failure prediction in composites," 53rd AIAA/ASME/ASCE/AHS/ASC Structures, Structural Dynamics, and Materials Conference, Honolulu, Hawaii, USA (April 23-26, 2012).

43. Silling, S. A., "Reformulation of elasticity theory for discontinuities and long-range forces," Journal of the Mechanics and Physics of Solids, 48, no. 1, pp. 175-209, (2000).

44. Silling, S. A. and Askari, E., "A meshfree method based on the peridynamic model of solid mechanics," Computers \& Structures, 83, no. 17-18, pp. 1526-1535, (2005).

45. Seleson, P. and Parks, M., "On the role of the influence function in the peridynamic theory," International Journal of Multiscale Computational Engineering, 9, no. 6, pp. 689-706, (2011).

46. Macek, R. W. and Silling, S. A., "Peridynamics via finite element analysis," Finite Element in Analysis and Design, 43, pp. 1169-1178, (2007). 